\title{
Exploration and Application of Innovative Engineering Talents Education Mode Based on CDIO
}

\author{
Changyou $\mathrm{Ma}^{1}$, Yiqun $\mathrm{Liu}^{2}$, Shilin $\mathrm{Pu}^{2}$, Qisheng Liu ${ }^{1}$, Guifu Wu ${ }^{1}$, Bingbing $\mathrm{Yan}^{1}$, Hong Zhao ${ }^{3, *}$ \\ 1 School of Mechanical Engineering, Jiamusi University, Jiamusi, China \\ 2 School of Automotive Engineering, Harbin Institute of Technology, Weihai, China \\ 3 School of Pharmaceutical, Jiamusi University, Jiamusi, China \\ *Corresponding author: mcyazh@126.com
}

\begin{abstract}
In order to comprehensively cultivate innovative engineering talents, the adoption the CDIO (Conceive, Design, Implement, and Operate) engineering education model is the latest achievement of international engineering education reform in recent years. This article adopts the CDIO training mode, takes students' practical ability, learning ability, employability, and innovative spirit as a main line, combines the characteristics of related professions, reforms the training mode of thermal energy and power engineering professionals, and highlights the combination of self-study and research. In self-study, it focuses on practicality and effectiveness, and builds an education model that integrates CDIO with innovative engineering and scientific talents. It is guided by social needs and is based on students' practical abilities. With the progress of times, a relatively complete training system is formed, which enables the students can adapt to the needs of the complex application talents brought by rapid development of modern science and technology and increasingly social and economic changes.
\end{abstract}

Keywords-CDIO; Innovative engineering talent; Education mode; Teaching practice

\section{INTRODUCTION}

In June 2006, Comrade Hu Jintao pointed out in his speech at the 13th Academician Conference of the Chinese Academy of Sciences and the 8th Academician Conference of the Chinese Academy of Engineering: "Innovative science and technology talents are creators of new knowledge, inventors of new technologies, and new disciplines. The founder of the company is a pioneer and pioneer in the development of new breakthroughs in science and technology and a valuable strategic resource for the development of the country." The engineering and technological talents are application-oriented scientists and technicians, and the current focus of higher engineering education reform is to cultivate Innovative engineering talents. The CDIO engineering education model is the latest achievement of the international engineering education reform in recent years. The CDIO (Conceive Concept-Design Implement Implementation-Operate Operation) training model emphasizes project design as the carrier, and all the content that needs to be learned and mastered is centered on the core of project design. It is beneficial to improve the current state of theoretical light practice in the current engineering education, and focuses on integrating individual,

Educational Science Research Project of Jiamusi University (JKA2013029), Planning subject of Heilongjiang Education Office (GBC1213084), Heilongjiang Province Higher Education Project of Basic Scientifc Research (2017-KYYWF-0568) and Education Teaching Research Project of Jiamusi University (2016JL1013). social, and systematic manufacturing technologies and basic principles to make it suitable for all fields of engineering. It can not only improve students' theoretical knowledge, but also improve students' life-long learning ability, team communication ability and large system control ability [1].

\section{ANALYSIS OF FOREIGN RESEARCH STATUS}

In October 2000, the four universities of MIT, the Swedish Royal Institute of Technology, Chalmers University of Technology in Sweden, and Linkoping University in Sweden, were jointly organized by Professor Edward F. Crawley of the American Academy of Engineering to form a multinational research group in Knut and Alice. Under the huge funding of nearly 16 million U.S. dollars, Wallenberg Foundation after four years of intensive research, exploration and practice, in 2004 co-founded the mode of engineering education reform, and at the same time established the CDIO International Cooperation Organization. CDIO is an abbreviation of Conceive, Design, Implementation, and Operate. CDIO mainly takes the entire product life cycle from product development to product operation as the carrier, allowing students to learn engineering theoretical knowledge, practical experience, and various capabilities through active, practical, and organic links between courses. [2]. In 2000, the CDIO program was first created at the Massachusetts Institute of Aeronautics and Astronautics, which was a milestone for the CDIO to put into practice. The Department of Aeronautics and Astronautics of MIT developed a series of training goals based on the quality requirements of aerospace people. According to the outline of the CDIO, a new outline for aerospace people was developed to reform curriculum, teaching, laboratories, etc. for the CDIO. Implementation has created a precedent. In 2001, South Africa joined the CDIO program, adjusted its training objectives according to the actual situation in South Africa, and set the CDIO's African Center at the University of Pretoria in South Africa to reform the machinery mainly at the University of Pretoria. With the Institute of Aerospace Engineering, at the same time, the implementation of the CDIO's achievements and experience will be extended throughout Africa to promote the development of CDIO in Africa [3]. The CDIO model has achieved very good results since it was implemented in dozens of universities headed by MIT. At present, according to statistics, more than 20 universities have joined the CDIO. These universities are distributed all over the world, including 
China, of course, and they continue to research and refine the CDIO model [4].

\section{RESEARCH OF DOMESTIC PROBLEMS}

Shantou University first joined the CDIO program in combination with the current status of its own talent cultivation model, and created the EIP-CDIO model. Gu elaborated on the concept of the new EIP-CDIO model and presented a set of implementation plans for the EIP-CDIO. Learning to learn [5]. Cha from Beijing Jiaotong University is representative of the research on industry-academia cooperation and internationalization in the field of engineering education. He has systematically and specifically introduced seven key standards of the 12 standards of CDIO. A preliminary analysis of the relationship between "CDIO" and "production-study cooperation" and "internationalization" of the engineering education reform strategy [6]. Li changed the traditional perspective and opened up a new path to interpret the CDIO from a historical perspective. He believes that the CDIO is one of many ways to solve current engineering education problems [7]. Prof. Wang Gang, vice president of Shanghai Second Polytechnic University, proposed that when introducing the CDIO concept, colleges and universities should build new talent training models and achieve CDIO diversification based on the basic conditions of the school and the actual conditions of student learning.[8] Tsinghua University's Professor of Industrial Engineering Gu Xueshen uses the CDIO method to teach and acquire practical experience through two continuous compulsory courses "Data Structure and Algorithms" and "Database System Principles" to refine a consideration of the department as a whole. Knowledge dissemination and creation model [9]. Wang Shuowang of the Beijing Normal University School of Education and Management, through an interpretation of the CDIO syllabus, analyzes its characteristics and discusses the implications of the CDIO model for the innovation of China's applied talent cultivation [10]. Subsequently, more and more scholars have promoted the concept of CDIO. There are curriculum reforms, such as computer courses, animation courses, mechanical principles courses, circuit and electronic courses, etc. There are also reforms in personnel training, such as innovative personnel training, software personnel training, application-oriented personnel training, etc. Gradually scholars have found that CDIO is not only applicable to engineering courses, the level is not limited to university undergraduates, and CDIO has embarked on a path of development.

\section{EXPLORATION AND PRACTICE OF TRAINING MODE}

This topic is based on the reform of innovative engineering and scientific personnel training model, the reform of our school's thermal and power engineering majors, the use of CDIO theory to study innovative engineering technology personnel training model, and the establishment of innovative engineering science and technology talent education curriculum system for college students. Improving students' knowledge structure, improving students' spirit of innovation, improving teachers' engineering practice, strengthening practical teaching, and reforming student evaluation systems.

\section{A. Optimize training plan and building new curriculum system}

Reforming the traditional personnel training model, focusing on education and teaching concepts, taking social needs as a guide, and cultivating students' practical abilities as the main line, to further optimize and improve training programs. Establish a new concept of the "Teaching for Learning" trinity of the CDIO, and carry out the personnel training model of research teaching, research experiments, science and technology competitions, research training, and project training. Through the "learning-experiment-innovationlearning" approach, a large number of innovative engineering and scientific talents with practical ability in high-level thermal and power engineering are trained. In the aspect of curriculum system construction, project implementation will be taken as the main course throughout the curriculum setting process. Plan and integrate various courses to build a new curriculum system based on the CDIO concept and organized around the project. Pay attention to innovative self-learning of team members, combine basic courses, professional basic courses and professional courses, combine experimental courses, production practice, graduation practice and graduation design, complete better design, and pay attention to the principles of engineering knowledge and technical reasoning. Consolidate student professional basic knowledge (thick basis); pay attention to the introduction of modern engineering science and technology development, introduction of multidisciplinary engineering application knowledge, is a student to understand the broader scientific principles (wide caliber), train students to be good at "conception-design- The ability to implement operate.

\section{B. Reforming teaching methods and methods}

To establish a student-centered concept and teach students to learn. With students as the center, all design tasks are student-oriented. Through self-learning, students turn to stage presentations in a small-scale way, so that all students exchange knowledge, as shown in Fig. 1. Not only can it improve students' ability to study independently and develop the habit of life-long learning, it also helps improve the overall strength. Advocate "doing high school" teaching methods. Through the combination of production, teaching and research, combination of inside and outside classes, and combination of inside and outside schools, students are allowed to form a positive interaction between the learning and application of knowledges. They use high-grade methods to guide younger students, carry out weekly learning sessions, and report learning. 


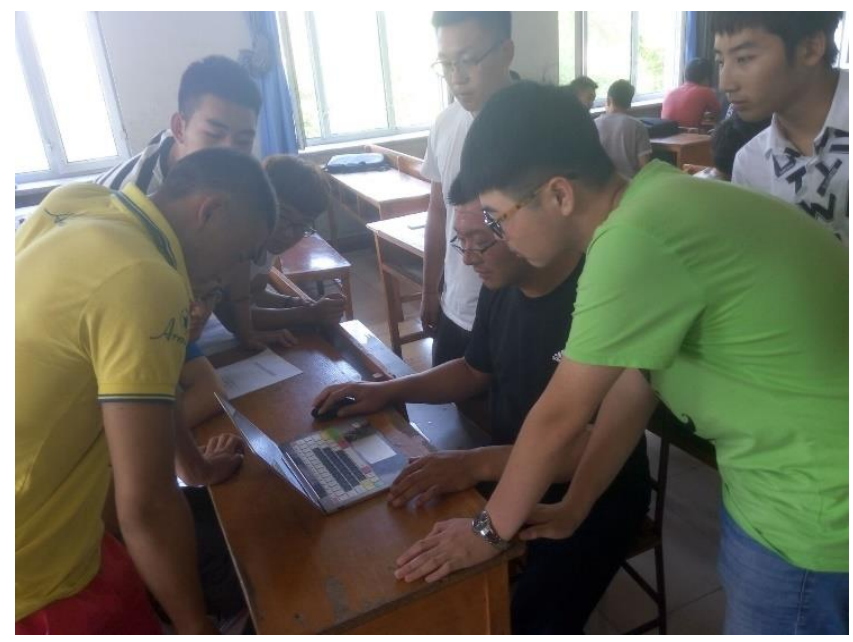

Fig. 1. The students group discussion.

\section{Intensifying practice education}

We will build a practical teaching system, adjust practical teaching links, and construct a practical teaching system that is suitable for training innovative engineering talents. Cultivate students' innovative spirit and practical ability. In the learning process, students can develop the ability to find problems, ask questions, and solve problems, and improve their practical and innovative abilities combining theory with practice. By participating in scientific research projects, students can learn about the latest research trends of disciplines, and determine their research direction as soon as possible based on interests and hobbies.

Improve students' emphasis on the practical process, through the processing and assembly of vehicles and engines, as shown in Fig. 2, so that students understand and proficient in the use of various processing tools to guide future design and development. Applying the theoretical knowledge learned to practice in an "integrated practical drill" is an important part of cultivating engineering students and their ability to innovate. The whole process can reflect the ability of comprehensive analysis to solve practical problems. Inspire students to give full play to the original spirit and guide students in their practice to continuously improve their ability to innovate.

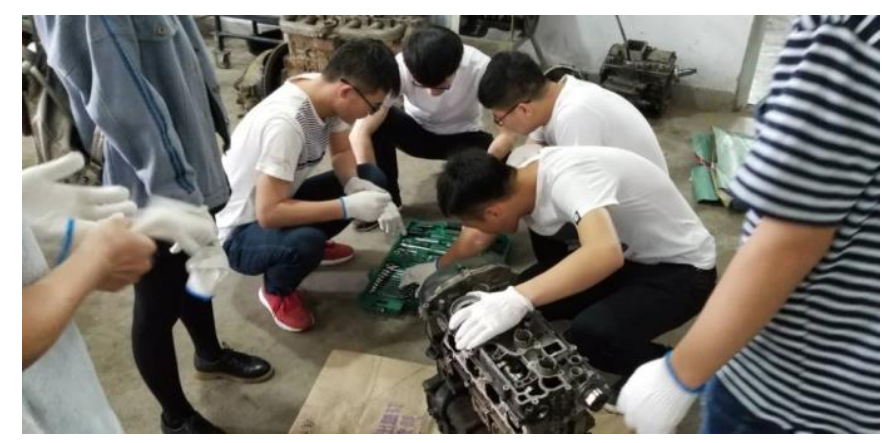

Fig. 2. Disassembly and assembly of vehicles and engines.

\section{Improving the instructor's engineering practice ability}

The cultivation of innovative engineering science and technology personnel requires a high-quality teacher team for protection. On the one hand, the introduction of "professionals" with corporate engineering backgrounds or engineers with rich practical experience in schools to teach in schools (at present, there are already three teachers in the profession who have long-term corporate work experience). Emphasizing the important role of young teachers in the development of higher engineering education. They are the backbone of training innovative engineering technology talents. They choose to send young teachers to large companies to practice or train, and to cultivate and improve the ability to solve practical engineering problems. Provide young teachers with opportunities for study and further education, provide opportunities for them to increase their engineering background, strengthen links with companies, and use companies as bridges to create concrete engineering practice environments. To improve the practical ability and application ability of engineering technology, improve the ability structure of the teaching staff, improve the pertinence and application of teaching, and train "dualqualified" teachers. On the other hand, teachers themselves should constantly change their educational concepts and establish innovative education concepts. They have a strong sense of innovation and innovation. They can stand at the forefront of innovation to teach and guide students and cultivate students' sense of innovation and innovative spirt, develop the habit of consciously experiencing innovation.

\section{E. Reforming student evaluation system}

Establish an index orientation that is conducive to the cultivation of students' innovative qualities. The indicator system of student evaluation under the premise of fully embodying the "comprehensive development in morality, intelligence, and physical development" should also reflect the quality elements that should be possessed by innovative talents, and the thinking, knowledge, and ability that should be possessed by innovative talents. Factors such as personality and personality are included in the evaluation system to form a development evaluation system that guides and motivates students to develop morally, intellectually, physically and comprehensively, and to enhance their overall quality of innovation. The examination system centered on rote learning and the rote memorandum-based examination system have been changed. Diversification of examination methods has been adopted and examination evaluation standards have been diversified.

\section{CONCLUSIONS}

This article constructed an education mode that integrates CDIO with innovative engineering and scientific personnel training. Establishing the new concept of the CDIO "Teaching and Learning" trinity, reforming the traditional talent training model, emphasizing the education and teaching concept, and guiding the society to the needs of students. Ability training is the main line, timely adding teachers' scientific research results into classroom teaching content, making it advancing with the times and forming a relatively complete training system, so that the students trained by this major can adapt to the rapid 
development of modern science and technology and the changing social economy of the complex application of talents demand.

\section{REFERENCES}

[1] Gao Xuemei, Sun Ziwen, Ji Zhicheng. The CDIO Method and the Reform of Higher Education in China[J]. Jiangsu Higher Education, 2008, (5): 69-71.

[2] Edward F. Crawley. The CDIO Syllabus: A Statement of Goals for Undergraduate Engineering Edueationg[EB/OL]. http://cdio.org/cdiosyllabus-rept/index.html, 2008-07-01.

[3] Wang Tianbao, Cheng Weidong. Research and Practice of Innovative Engineering Talents Training Model Based on CDIO -- The Practice of Engineering Education Reform of Chengdu University of Information and Technology[J]. Higher Engineering Education Research, 2010, (1): 25-31.

[4] Gu Peihua, Shen Minfen, Lu Xiaohua. Re-understanding of Engineering Education: International CDIO Training Model and Method[M]. Beijing: Higher Education Press, 2009.

[5] Gu Peihua, Shen Minfen, Li Shengping, et al. From CDIO to EIP-CDIO -- Exploration of Engineering Education and Talent Cultivation Mode of Shantou University[J]. Higher Engineering Education Research, 2008, (1): $12-20$.

[6] Cha Jianzhong. Engineering Education Reform Strategy "CDIO" and Industry-University Cooperation and Internationalization [J]. Chinese University Teaching, 2008, (5): 16-19.

[7] $\mathrm{Li}$ Manli. Interpretation of CDIO and its application prospects with history[J]. Educational Research, Tsinghua University, 2008, (5): 78-87.

[8] Wang Gang. Interpretation and Thinking of CDIO Engineering Education Model[J]. China Higher Education Research, 2009, (5): 86-87.

[9] Gu Xuebiao. CDIO of Linking Theory and Practice -- Exploration of Innovative Engineering Education of Tsinghua University[J]. Research in Higher Education of Engineering, 2009, (1): 11-23.

[10] Wang Shuowang, Hong Chengwen. CDIO: The Classic Model of Engineering Education at the Massachusetts Institute of Technology Based on the Interpretation of the CDIO Curriculum Outline [J]. Chinese Higher Education Research, 2009, (8): 116-119. 